\title{
HABERMAS NA LITERATURA DE CIÊNCIA DA INFORMAÇÃO: INVESTIGAÇÃO DAS PUBLICAÇÕES NA "LIBRARY AND INFORMATION SCIENCE ABSTRACTS" (LISA)
}

\author{
HABERMAS EN LA LITERATURA DE LA CIENCIA DE LA \\ INFORMACIÓN: PUBLICACIONES DE INVESTIGACIÓN EN \\ "LIBRARY AND INFORMATION SCIENCE ABSTRACTS" (LISA)
}

Marianna Zattar - mariannazattar@gmail.com Doutoranda em Ciência da Informação no Instituto Brasileiro de Informação em Ciência e Tecnologia (IBICT). Bibliotecária da Biblioteca Central da Universidade Federal do Estado do Rio de Janeiro (UNIRIO).

Clóvis Ricardo Montenegro de Lima - clovis.mlima@uol.com.br Pós-doutor em Ciência da Informação pelo Instituto Brasileiro de Informação em Ciência e Tecnologia (IBICT). Pesquisador adjunto do IBICT.

\section{RESUMO}

Introdução: Neste trabalho são apresentadas questões relativas a Jürgen Habermas na literatura de Ciência da Informação, com ênfase na discussão sobre a relação entre informação e linguagem e com a identificação dos principais assuntos da informação encontrados.

Objetivo: Apresentar a utilização de Habermas na Literatura de Ciência da Informação.

Metodologia: Pesquisa dos textos publicados na Library and Information Science Abstracts.

Resultados: Indicaram a utilização e influência de Jürgen Habermas na Ciência da Informação; com ênfase na "Teoria do Agir Comunicativo" e no conceito de "Esfera Pública".

Conclusões: Jürgen Habermas pode fornecer referências teóricas e metodológicas para estudos e pesquisas em Ciência da Informação, especialmente aqueles que demandam visões críticas ou inovadoras. 
Palavras-chave: Habermas. Ciência da informação. Library and information science abstracts.

\section{INTRODUÇÃO}

A investigação do lugar de Jürgen Habermas na literatura da Ciência da Informação implica em pensar os dois lados desta relação. De um lado, o filósofo e sociólogo alemão herdeiro da tradição da Escola de Frankfurt, autor de uma vasta obra e considerado um dos maiores pensadores vivos. De outro, uma ciência social aplicada que vive em constantes disputas epistemologias e metodológicas.

A escolha de Habermas é a escolha de uma via critica. A sua teoria critica apresenta um fundamento humanista para as ciências sociais. A sua teoria do agir baseada na linguagem propõe o entendimento a partir da relação discursiva com o outro. A relação entre crítica, ação e sistema em Habermas abre grandes possibilidades teóricas e metodológicas a serem exploradas, especialmente no que se refere à administração discursiva de organizações complexas.

González de Gómez (2009, p. 115) afirma que uma das razões para se ir a Habermas é a sua proposta de divisão de trabalho entre a Filosofia e as Ciências Humanas e Sociais em suas abordagens inter e pós-disciplinares. Segundo a autora as ciências ditas sociais não o são somente por se tratar de uma construção de segundo grau sobre a produção social de sentido, mas as questões com que lidam são expressão daquilo que acontece no tempo e na dimensão atual de um processo social. É nessa direção que pensar o presente remete à linguagem e a informação.

Habermas enuncia assim a tarefa de uma Teoria Crítica da Sociedade ao concluir a sua Teoria do Agir Comunicativo:

O propósito da presente investigação é introduzir a teoria da ação comunicativa que dê razões aos fundamentos normativos de uma teoria crítica da sociedade. A teoria da ação comunicativa representa uma alternativa a filosofia da história. A teoria da ação comunicativa constitui um marco dentro do qual se pode retomar aquele projeto de estudos interdisciplinares sobre o tipo seletivo de racionalização que representa a modernização capitalista (HABERMAS, 1987, p. 562-563). 


\section{HABERMAS NA LITERATURA DE CIÊNCIA DA INFORMAÇÃO}

A pesquisa é realizada na base de dados referencial internacional "Library and Information Science Abstracts" (LISA). Essa base indexa mais de 400 títulos de periódicos de mais de 68 países e em mais 20 idiomas diferentes. A pesquisa buscou a palavra "Habermas" nos resumo dos artigos.

Quadro 1 - Estratégias na LISA

\begin{tabular}{|l|l|}
\hline \multicolumn{1}{|c|}{ Estratégia/Base } & \multicolumn{1}{c|}{ LISA } \\
\hline Recorte & Pesquisa retrospectiva \\
\hline Tipo de pesquisa & Avançada \\
\hline Palavra-chave & Habermas \\
\hline Campo & Resumo \\
\hline Tipo de documento & Artigo de periódico (Journal Article) \\
\hline Revisado por especialistas & Sim \\
\hline Tipo de fonte & Periódico científico (Scholarly Journals) \\
\hline Data da pesquisa & 16 set. 2013 \\
\hline
\end{tabular}

Fonte: Autores.

Cabe ressaltar que a escolha do resumo como filtro de pesquisa ocorre devido à possibilidade de recuperar publicações com a representação temática, em geral, feita pelos próprios autores. A partir da estratégia anteriormente apontada, na busca propriamente dita obteve-se 66 artigos, dos quais 53 estão publicados em periódicos acadêmicos, 51 eram revisados por especialistas em periódicos indexados pela LISA, sendo que destes, 49 não são duplicatas. 
Gráfico 1 - Distribuição temporal das publicações na LISA

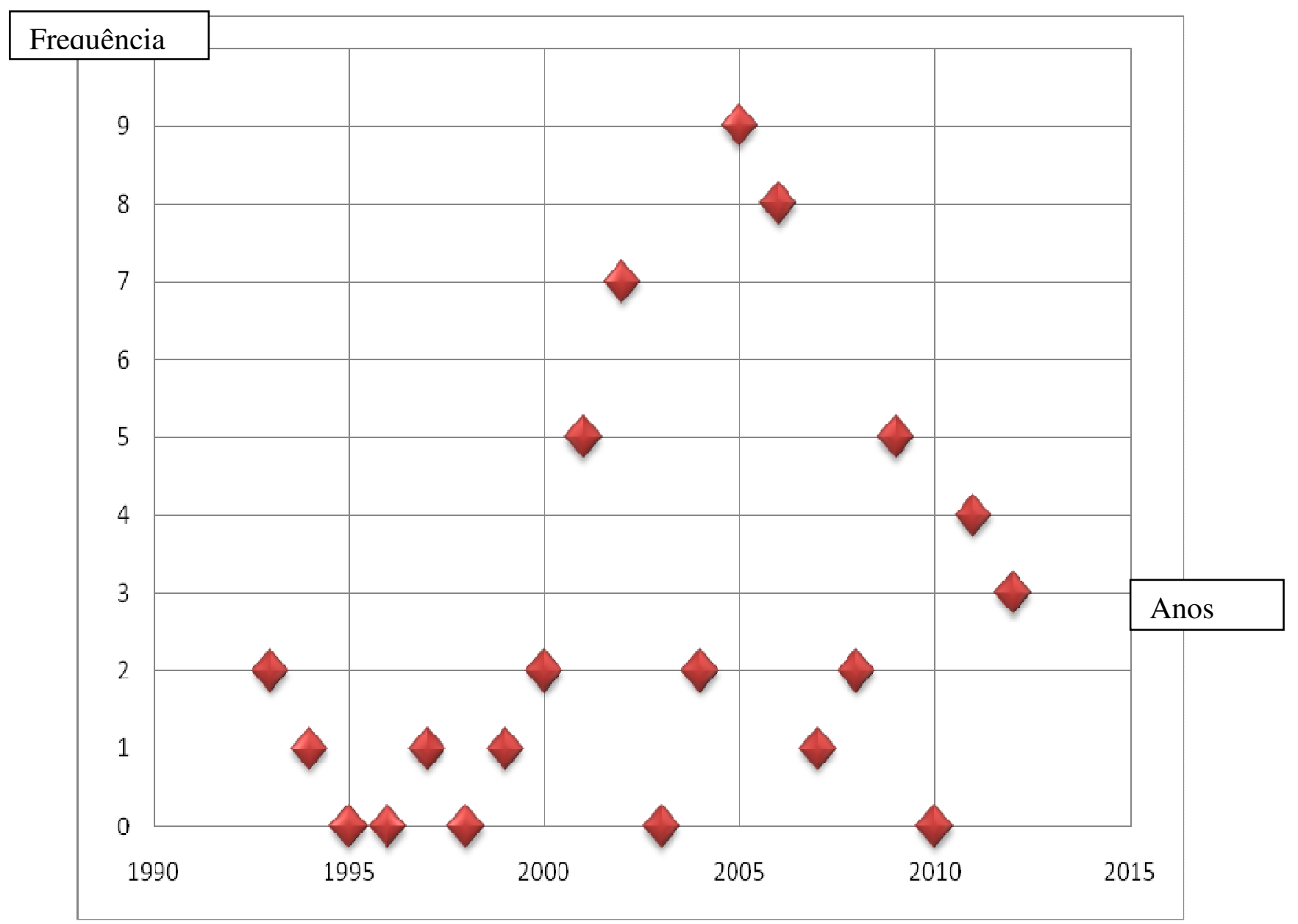

Fonte: Autores.

A primeira informação relevante sobre estas publicações diz respeito a sua distribuição temporal. A série recuperada neste estudo começa em 1993, o que significa que alguns artigos referenciados em Habermas têm 20 anos. Em termos biográficos cabe comentar que isto corresponde não apenas ao Habermas após a sua "guinada lingüística", mas também a sua "guinada pragmática". Além disso, o Gráfico 1 indica que os artigos referenciados em Habermas são contínuos nas duas ultimas décadas.

Habermas (1990, p. 15) comenta que a passagem do paradigma da filosofia da consciência para a filosofia da linguagem constitui um corte profundo: a partir deste momento os sinais lingüísticos, que serviam apenas como instrumento e equipamento de representações, adquirem como reino intermediário dos significados lingüísticos, uma dignidade própria. As relações entre linguagem e mundo, entre proposição e estados de coisas, substituem as relações sujeito-objeto. O trabalho de constituição do mundo deixa 
de ser uma tarefa da subjetividade transcendental para se transformar em estruturas gramaticais.

A nova compreensão da linguagem obtém relevância paradigmática graças, principalmente, às vantagens metódicas que exibe frente à filosofia do sujeito, cujo acesso às realidades da consciência é inevitavelmente introspectivo. É possível alguém se certificar da validade intersubjetiva de observações através da prática experimental, portanto, através da transformação regulada de percepções de dados. Uma objetivação semelhante ocorre quando empreendemos a análise de representações e pensamentos seguindo as formações gramaticais, graças às quais eles são expressos (HABERMAS, 1990, p. 55).

Através da passagem para a pragmática formal a analise da linguagem consegue reaver a amplitude e os questionamentos da filosofia do sujeito, que tinham sido dados como perdidos. O próximo passo consiste na análise dos pressupostos gerais que devem ser preenchidos para que os participantes da comunicação possam entrar em entendimento sobre algo no mundo. Estes pressupostos pragmáticos do entendimento apresentam como peculiaridade uma grande dose de idealização.

A guinada pragmática oferece a saída para aquilo que Habermas (1990, p. 57) chama de recuperação da abstração estruturalista. As realizações transcendentais não se retiram para os sistemas de regras gramaticais enquanto tais: a síntese lingüística é muito mais o resultado da obra construtiva do entendimento, a qual se efetua através das formas de intersubjetividade rompida. As regras gramaticais garantem a identidade de significado das expressões lingüísticas, mas têm de deixar espaço para um uso individualmente nuançado e inovador destas expressões, cujo significado possui uma identidade apenas suposta.

Faz-se a apresentação da distribuição dos artigos por periódico na LISA no Quadro 2. 
Quadro 2 - Distribuição total por periódico na LISA

\begin{tabular}{|c|c|}
\hline Título da publicação & Número de Artigos \\
\hline Journal of Information Technology & 4 \\
\hline Information Research & 3 \\
\hline Library Quarterly & 3 \\
\hline Media, Culture \& Society & 3 \\
\hline First Monday & 3 \\
\hline Information Technology \& People & 3 \\
\hline Technical Communication Quarterly & 3 \\
\hline European Journal of Information Systems & 2 \\
\hline Information, Communication \& Society & 2 \\
\hline Information Technology for Development & 2 \\
\hline European Journal of Communication & 2 \\
\hline Cataloging and Classification Quarterly & 2 \\
\hline Journal of Information, Communication and Ethics in Society & 2 \\
\hline Library Philosophy and Practice & 2 \\
\hline Information Polity & 1 \\
\hline Journal of Knowledge Management & 1 \\
\hline Journal of the American Society for Information Science and Technology & 1 \\
\hline New Library World & 1 \\
\hline The Information Society & 1 \\
\hline Journal of Documentation & 1 \\
\hline Information and Communications Technology Law & 1 \\
\hline Information Processing and Management & 1 \\
\hline Information Society & 1 \\
\hline Journal of Communication Management & 1 \\
\hline Journal of Electronic Commerce in Organizations & 1 \\
\hline Journal of Librarianship and Information Science & 1 \\
\hline Public Library Quarterly & 1 \\
\hline TOTAL & 49 \\
\hline
\end{tabular}

Fonte: Autores.

Os 49 artigos recuperados na LISA estão publicados em 27 periódicos, tal como apresentado no quadro 2. Desses 27 periódicos, 16 estão classificados em estratos 
atribuídos pela Coordenação de Aperfeiçoamento de Pessoal de Ensino Superior (CAPES) do Ministério da Educação (MEC) - gráfico 2.

Gráfico 2 - Distribuição de frequência dos periódicos por estrato

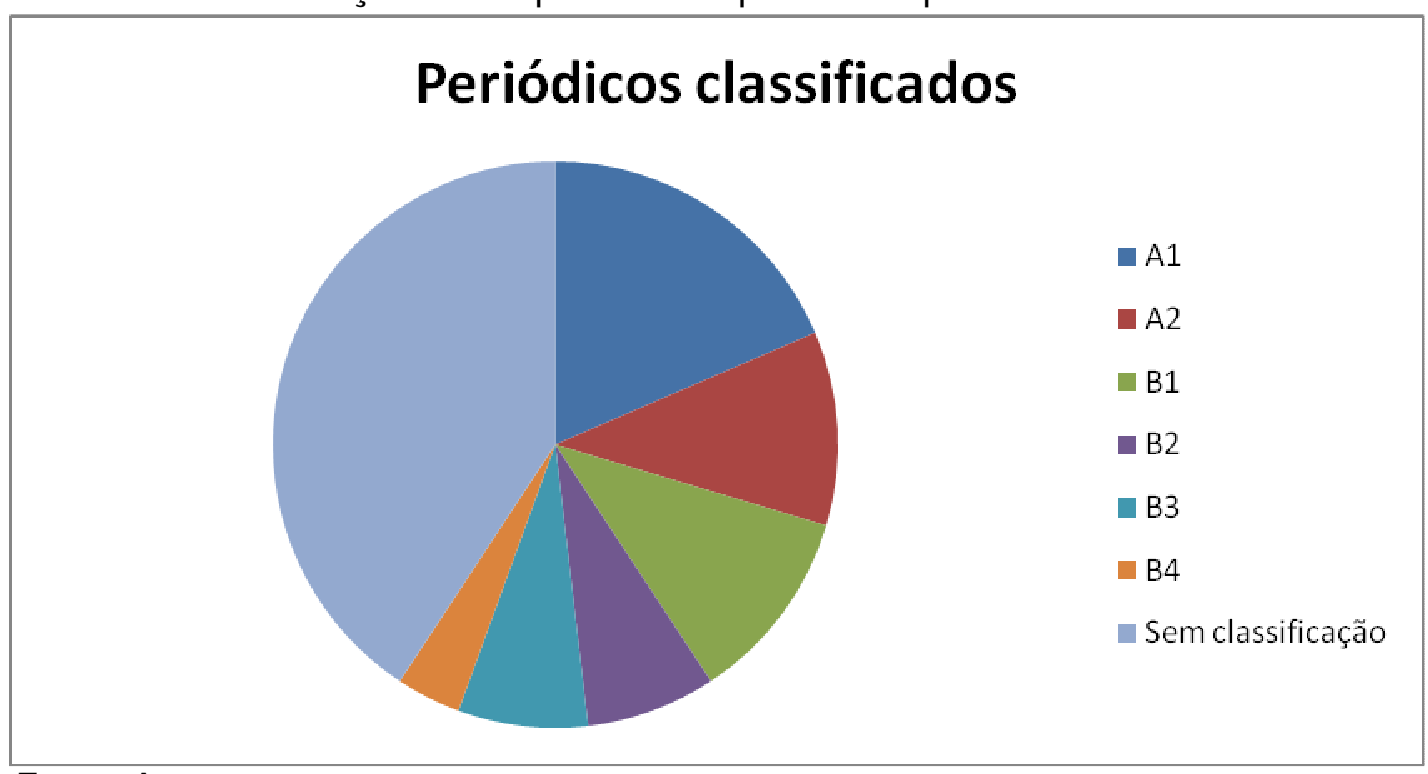

Fonte: Autores.

Dos 27 periódicos relacionados, $18,5 \%$ estão classificados com o estrato $A 1$, $11,1 \%$ nos estratos $A 2$ e $B 1,7,4 \%$ no $B 1$ e nos estratos $B 3,3,7 \%$ no estrato $B 4$ e aproximadamente $40,7 \%$ não possui classificação.

As publicações recuperadas na LISA podem ser divididas à luz da classificação da CAPES (quando o periódico sofre avaliação): "Ciências Exatas e da Terra", "Ciências Sociais Aplicadas", "Engenharias", "Linguísticas, Letras e Artes", "Multidisciplinar". A distribuição de frequência dos periódicos por área do conhecimento permite que seja vislumbrada a concentração e a dispersão entre as áreas.

Quadro 3 - Distribuição de frequência dos periódicos por área do conhecimento

\begin{tabular}{|l|c|}
\hline \multicolumn{1}{|c|}{ Área do conhecimento } & Distribuição de frequência dos periódicos \\
\hline Ciências Exatas e da Terra & $14 \%$ \\
\hline Ciências Sociais Aplicadas & $29 \%$ \\
\hline Engenharias & $7 \%$ \\
\hline Linguísticas, Letras e Artes & $3 \%$ \\
\hline Multidisciplinar & $3 \%$ \\
\hline Não classificada no Qualis & $40 \%$ \\
\hline
\end{tabular}

Fonte: Autores. 
Os quatro periódicos classificados em "Ciências Exatas e da Terra", sendo todos da subárea "Ciência da Computação". São eles: "European Journal of Information Systems", "Information, Communication \& Society", "Information Polity", "Information Technology for Development" concentram sete artigos.

Oito periódicos estão classificados nas chamadas "Ciências Sociais Aplicadas". Estes periódicos são intitulados da seguinte forma: "Journal of Knowledge Management", "Information Research", "Library Quarterly", "Media, Culture \& Society", "Journal of the American Society for Information Science and Technology", "New Library World", "First Monday", "European Journal of Communication" e juntos somam dezessete artigos.

$\mathrm{Na}$ "Engenharias" estão classificados dois periódicos: "Information Technology \& People", com três artigos, e o "Journal of Information Technology", com quatro artigos.

Nas áreas do conhecimento denominadas "Linguísticas, Letras e Artes" e "Multidisciplinar" enquadram-se dois artigos com os respectivos periódicos: "The Information Society" e o "Journal of Documentation". Com relação ao periódico classificado como multidisciplinar, ele é passível de que seja incorporado no desdobramento denominado "sociais e humanidades".

O total de dezesseis artigos estão nos periódicos que não possuem classificação, estão o "Cataloging and Classification Quarterly", o "Information and Communications Technology Law", o "Information Processing and Management", o "Information Society", o "Journal of Communication Management", o "Journal of Electronic Commerce in Organizations", o "Journal of Information, Communication and Ethics in Society", o "Journal of Librarianship and Information Science", o "Library Philosophy and Practice", o "Public Library Quarterly" e o "Technical Communication Quarterly".

\section{LINGUAGEM E INFORMAÇÃO}

A informação é um campo discursivo para as mais diversas perspectivas, devido ao fato de assumir um papel metafórico que reúne e remete as novas figuras da mediação de toda ação e agência coletiva. A linguagem parece oferecer um novo horizonte para o entendimento das relações entre economia, direito e informação, permitindo que, no espaço dessas relações mediadas pela linguagem, sejam confrontadas as plurais 
demandas de reformulação ou desativação de conceitos habitualmente abordados pelas ciências sociais, tais como trabalho, mercadoria e poder.

A guinada lingüística não é outra coisa que uma das expressões da época em que é dada ao ser humano a oportunidade de ter acesso à experiência de seu próprio ser lingüístico; não de seu ser produtor de tais proposições ou tais textos, mas a experiência radical da dimensão lingüística de sua existência simbólica. A guinada lingüística amplia os domínios da linguagem, da comunicação e da informação nos espaços do trabalho, da produção e da política. Cabe questionar conflitos e mecanismos de controle que definem regimes de informação, formas de organização e processos de produção e inovação que, no médium da linguagem, cercam ou potencializam as formas de vida (LIMA; GONZALEZ DE GÓMEZ, 2010, p. 153).

A informação tem para Habermas uma dupla ancoragem: a sócio-cognitiva e a instrumental-estratégica. Por um lado, a informação está ancorada na temporalidade que atrela corpo e cultura numa configuração diferenciada da aisthesis e permite a abertura de múltiplas perspectivas sobre o mundo. Associada a algumas das plurais possibilidades heurísticas das ações cotidianas e especializadas, a informação designa uma diferença que se instala nas experiências de confronto entre as expectativas prévias e do que acontece nas relações atuais com o mundo. Por outro lado, a informação, enquanto codificada, reconstitui através dos meios, nas zonas de trocas e negociação entre os sistemas e os mundos da vida - mediação, porém constituída numa relação histórica e não "lógica", plausível, então, de ambivalências e de transformações (GONZALEZ DE GÓMEZ, 2009, p. 117-118).

A informação está relacionada a uma instância de constante reabertura das relações entre o mundo da vida e o mundo (GONZALEZ DE GÓMEZ, 2009, p. 119-120). O conceito abstrato de mundo é condição necessária para que os sujeitos que agem comunicativamente tenham condições de chegar a um entendimento mútuo sobre o que acontece no mundo ou sobre o que deve ser feito nele. Com essa prática comunicativa, eles ao mesmo tempo se asseguram do contexto vital que têm em comum (o mundo da vida intersubjetivamente partilhado) (HABERMAS, 2012, p. 40).

Assim as informações constituem uma espécie de zona de negociação entre os mundos da vida e o mundo. Na forma que esta zona só é acessível através de temas e em situações singulares, demarcadas pelos interesses e disposições de um ator social. 
Com isso, a descrição lingüística, está sempre em dependência do que o mundo "decide" comunicar (GONZALEZ DE GÓMEZ, 2009, p. 119-120).

Por outro lado, a informação, codificada e imersa nos meios, opera no domínio dos sistemas da administração e da economia, em exercícios funcionais instrumentais, e nas zonas de intermediação entre o sistema e os mundos da vida (GONZALEZ DE GÓMEZ, 2009, p. 119-120). Habermas tem a sociedade como contextos de ação estabilizados de modo sistêmico de grupos integrados socialmente. A evolução social acontece como processo de diferenciação entre mundo da vida e sistema, sendo o primeiro reduzido a um subsistema entre outros e o segundo desligado das estruturas de integração social (PINZANI, 2009, p. 110).

O processo de "colonização do mundo da vida" implica na substituição da regulação social mediada pela interação lingüística, pela regulação do poder e do dinheiro, do Estado e da economia. Em função da centralidade da interação lingüística na práxis social, a ação comunicativa é um constructo que integra múltiplas visões de mundo e de indivíduos, e essa multiplicidade é relevante para a compreensão do fenômeno organizacional. Permite que se verifiquem contradições nas relações interpessoais nem sempre enfocadas pelos estudos organizacionais, pois a idéia de distorção comunicativa, antes de ser um mero problema de comunicação organizacional, reflete a dificuldade de reconhecimento do outro enquanto sujeito competente, enquanto membro integrante de uma mesma comunidade cultural (VIZEU, 2005, p. 15).

$\mathrm{Na}$ medida em que os participantes da comunicação compreendem aquilo sobre o que se entendem como algo em um mundo, como algo que se desprende do pano de fundo do mundo da vida para se ressaltar em face dele, o que é explicitamente sabido separa-se das certezas que permanecem implícitas, os conteúdos comunicados assumem o caráter de um saber que se vincula a um potencial de razões, pretende validade e pode ser criticado, isto é, contestado com base em razões (HABERMAS, 1989, p. 169).

Habermas (2004, p. 65) inclui Wilhem Von Humboldt como fonte para sua teoria da linguagem, que distingue três funções da linguagem: a função cognitiva de formar pensamentos e representar fatos; a função expressiva de exprimir sentimentos e suscitar sensações; e a função comunicativa de comunicar algo, levantar objeções e produzir acordos. A interação dessas funções é representada de modo diferente dos pontos de 
vista semântico e pragmático. A análise semântica das organizações de conteúdos lingüísticos se concentra na visão de mundo lingüística, e a análise pragmática de um entendimento mútuo entre interlocutores põe a conversação em primeiro plano.

Habermas (1987, p. 367) fala de agir estratégico e agir comunicativo não somente para designar dois aspectos analíticos sob os quais uma mesma ação pode descrever-se como um processo de recíproca influência por parte de oponentes que atuam estrategicamente, de um lado, e como processo de entendimento entre membros de um mesmo mundo da vida, de outro. Fala isso porque as ações sociais concretas podem distinguir-se de acordo com o que os participantes adotem, ou bem uma atitude voltada ao êxito, ou bem uma atitude voltada ao entendimento. Estas atitudes, nas circunstâncias apropriadas, podem ser identificadas.

Os tipos de interação distinguem-se de acordo com os mecanismos de coordenação da ação: é preciso saber se a linguagem natural é usada apenas como meio para a transmissão de informações ou também como fonte de integração social. No primeiro caso trata-se, no entender de Habermas (1990, p. 71), de agir estratégico; e no segundo caso, de agir comunicativo. No caso de integração social a força consensual do entendimento lingüístico, isto é, as energias de ligação da própria linguagem, tornam-se efetivas para a coordenação das ações, ao passo que no caso de transmissão de informações a coordenação depende da influência dos atores uns sobre os outros e sobre a situação da ação, a qual é veiculada através de atividades não-lingüísticas.

A possibilidade de escolher entre agir comunicativo e agir estratégico é abstrata porque ela só está dada na perspectiva contingente do ator individual. Na perspectiva do mundo da vida a que pertence cada ator não é possível dispor livremente desses modos de agir, pois as estruturas simbólicas de todo mundo da vida reproduzem-se sob as formas de tradição cultural, da integração social e da socialização - e esses processos só podem efetuar-se por meio do agir orientado para o entendimento mútuo. Não há outro meio equivalente que seja capaz de preencher essas funções. A escolha entre agir comunicativo e agir estratégico só está em aberto num sentido abstrato, isto é, caso a caso (HABERMAS, 1989, p. 125).

A passagem para a argumentação encerra algo de antinatural: o rompimento com a ingenuidade das pretensões de validade erguidas diretamente e cujo reconhecimento intersubjetivo depende da prática comunicativa cotidiana. $\mathrm{Na}$ argumentação as 
pretensões de validade pelas quais os agentes se orientam sem problemas na prática cotidiana são tematizadas e problematizadas.

Habermas (2004, p. 101) destaca que a racionalidade discursiva cria uma correlação entre as estruturas ramificadas da racionalidade do saber, do agir e da fala ao concatenar as raízes proposicionais, teleológicas e comunicativas. Nesse modelo de estruturas nucleares engrenadas umas nas outras, a racionalidade discursiva deve seu privilégio não a uma operação fundadora, mas a uma operação integradora. Sendo uma forma reflexiva de agir comunicativo, a racionalidade corporificada no discurso sobrepõese à racionalidade comunicativa encarnada nas ações cotidianas.

Habermas (1990, p. 72) diz que o entendimento através da linguagem funciona da seguinte maneira: os participantes da interação unem-se através da validade pretendida de suas ações de fala ou tomam em consideração os dissensos constatados. Através de suas ações de fala são levantadas pretensões de validade criticáveis, as quais apontam para um reconhecimento intersubjetivo. A oferta contida num ato de fala adquire força obrigatória quando o falante garante, através de sua pretensão de validade situada, que está em condições de resgatar essa pretensão, caso seja requerido, empregando o tipo correto de argumento.

\section{OS ASSUNTOS DA INFORMAÇÃO SOB A PERSPECTIVA DE HABERMAS}

No âmbito dos assuntos da informação sob a perspectiva de Habermas é empreendida uma estruturação dos termos utilizados pela Lisa na indexação (representação temática) dos artigos localizados na pesquisa feita. 
Gráfico 3 - Assuntos na LISA

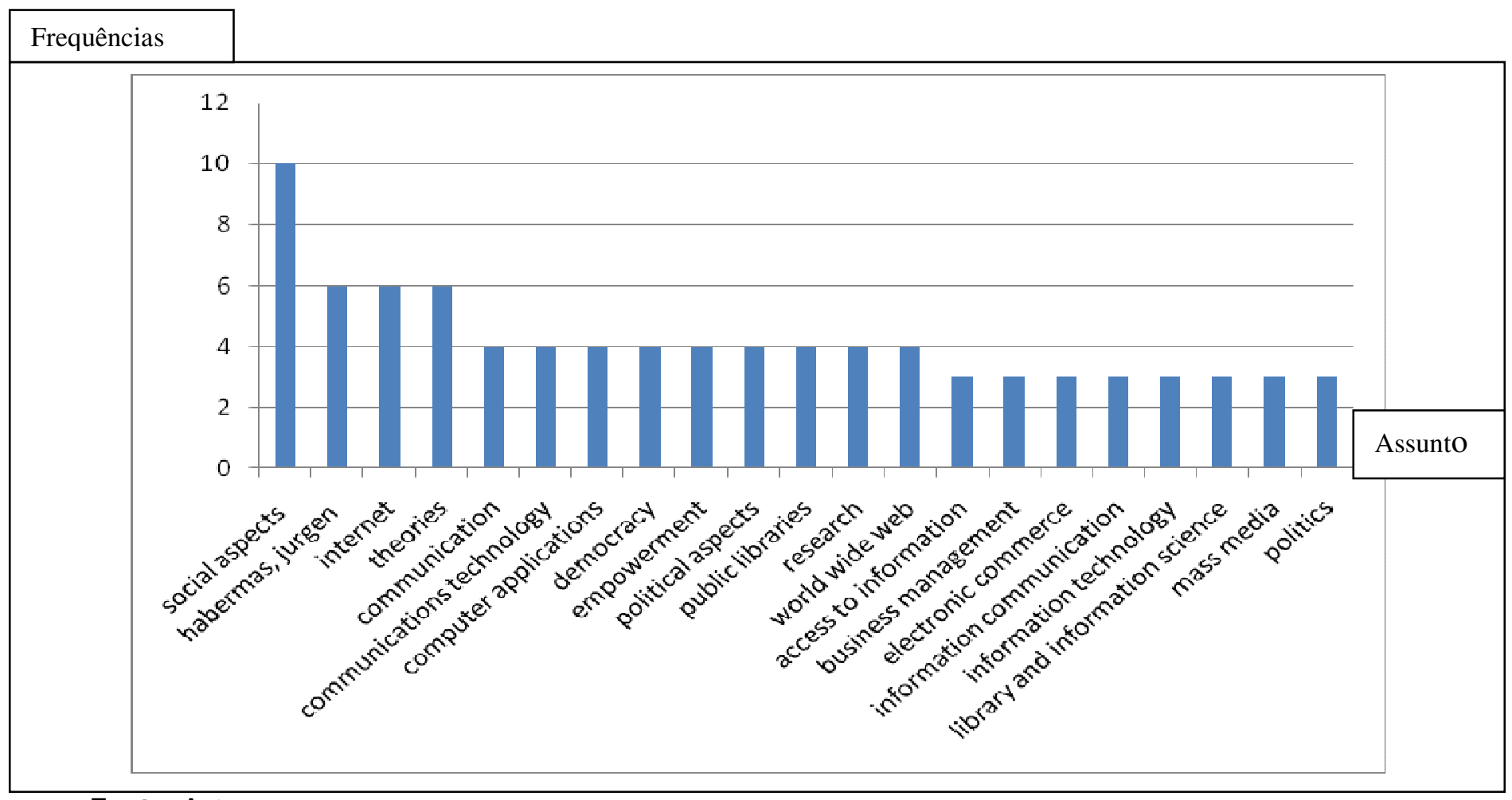

Fonte: Autores.

Quanto aos assuntos, com base na indexação da LISA, percebe-se que os mais utilizados são: social aspects, "habermas, jurgen", internet e theories - em português: aspectos sociais, "habermas, jurgen", internet e teorias. Estes assuntos podem ser relacionados ao desenvolvimento teórico-conceitual que Habermas proporciona nas discussões em torno do "discurso", "mundo da vida", "teoria do agir comunicativo", "ação comunicativa", “intersubjetividade", "esfera pública" e "emancipação". Particularmente, com relação aos artigos publicados sob a perspectiva da "internet" como termo escolhido para a representação, em geral, a internet é tratada com a perspectiva da "esfera pública".

Conforme exposto anteriormente, as publicações recuperadas na LISA podem ser divididas à luz da classificação da CAPES (quando o periódico sofre avaliação): "Ciências Exatas e da Terra", "Ciências Sociais Aplicadas", "Engenharias”, "Linguísticas, Letras e Artes", "Multidisciplinar". A distribuição de frequência dos artigos por área do conhecimento permite que seja vislumbrada aos assuntos mais gerais aos quais os artigos estão inseridos. 
Quadro 4 - Distribuição de frequência dos artigos por área do conhecimento

\begin{tabular}{|l|c|}
\hline \multicolumn{1}{|c|}{ Área do conhecimento } & Distribuição de frequência dos artigos \\
\hline Ciências Exatas e da Terra & $14 \%$ \\
\hline Ciências Sociais Aplicadas & $34 \%$ \\
\hline Engenharias & $14 \%$ \\
\hline Linguísticas, Letras e Artes & $2 \%$ \\
\hline Multidisciplinar & $2 \%$ \\
\hline Não classificada no Qualis & $32 \%$ \\
\hline
\end{tabular}

Fonte: Autores.

Os artigos publicados nos periódicos classificados em "Ciências Exatas e da Terra concentram sete artigos que abordam os assuntos: "comunicação", "gestão do conhecimento", "tecnologia da informação", "infra-estrutura" e "participação política". Segundo os respectivos autores as principais teorias de Habermas são: "emancipação", "ação social”, "intersubjetividade" e "esfera pública".

Dentre os principais assuntos dos artigos das "Ciências Sociais Aplicadas" estão: "comunicação", "mídia", “internet”, "comportamento informacional”, "sistema de informação", "aprendizagem, "democracia”, "epistemologia”, "organização do conhecimento", "sociologia" e "biblioteca". Na perspectiva da utilização de Habermas, pode-se notar que o autor é utilizado de forma mais geral, com destaque para "esfera pública" e o "agir comunicativo".

$\mathrm{Na}$ "Engenharias" estão quatro artigos que tratam de "tecnologia da informação", "e-commerce" e "sistema de informação" e utilizam como aportes teóricos fornecido por Habermas "emancipação" e o "agir comunicativo".

Nas áreas do conhecimento denominadas "Linguísticas, Letras e Artes" e "Multidisciplinar" enquadram-se dois artigos. O primeiro com um artigo sobre "Tecnologia da informação" que utiliza o "discurso" e o segundo sobre "Competência informacional" e utiliza o conceito de "Esfera pública". Com relação ao periódico classificado como multidisciplinar, ele é passível de que seja incorporado no desdobramento denominado "sociais e humanidades".

Nos dezesseis artigos que estão nos periódicos que não possuem classificação encontram-se questões que vão desde "desenvolvimento de coleção", até "democracia", 
"recuperação da informação", "usuário" etc. Na utilização de Habermas destaca-se o "agir comunicativo".

Com relação aos temas da Ciência da Informação destacam-se aqueles em torno dos problemas e questões da Biblioteconomia e da Documentação, tais como: a biblioteca e os sistemas de informação. Os dois artigos mais antigos estão publicados no mesmo periódico americano, o "Cataloging and Classification Quarterly". Este periódico dedica um número especial para os trabalhos do "Terceiro Simpósio Annette Lewis Phinazee".

O simpósio tem como temática a educação para os serviços técnicos e espera relacionar a teoria em prática nos anos de 1990. Com isso, embora o periódico tenha como proposta central abranger textos em torno da "catalogação" e da "classificação" no ambiente biblioteconômico, os artigos tratam de temas como "desenvolvimento de coleções", nos quais Habermas é utilizado para sustentar a questão das trocas comunicativas no desenvolvimento de políticas de desenvolvimento de coleções. Outros três são publicados na década de 90 na "Technical Communication Quarterly" utilizando como base teórica a Teoria do Agir Comunicativo de Habermas.

Nos anos 2000 há um crescimento significativo das publicações, destacando-se o elevado número (proporcional) das publicações, no ano de 2005 e 2006, respectivamente com 9 e 8 artigos. Cabe observar, entretanto, que nesta oportunidade tem destaque questões relacionadas à "Esfera Pública". Os artigos recuperados tratam de questões referentes ao ambiente web, a internet e às bibliotecas públicas.

\section{CONSIDERAÇÕES FINAIS}

O que a investigação na base de dados LISA mostra é que Jürgen Habermas vem sendo usado de modo regular nos últimos vinte anos como uma referência na literatura especializada para os mais diversos assuntos. Os 49 artigos encontrados são uma importante fonte de pesquisa para aqueles que, dentro da Ciência da Informação, se interessam por uma abordagem crítica ou por fundamentos humanísticos.

A mudança de perspectiva da filosofia da consciência para a filosofia da linguagem constitui-se em poderoso instrumento de crítica da informação. $O$ abandono da visão funcionalista e instrumental pode ser compensado por uma reconstrução dos modos de 
ação a partir dos recursos dos mundos da vida. A inclusão discursiva das perspectivas críticas pode contribuir para uma abordagem racional ampliada.

A discussão sobre informação a partir da filosofia da linguagem não é recente, e não está restrita a abordagem de Habermas. Entretanto, todos aqueles que querem compreender a informação para além de um redutor de incerteza, poderão encontrar na Teoria do Agir Comunicativo e na obra de Habermas um terreno fértil e instigante para investigar. A começar por uma noção de linguagem com funções expressivas e comunicativas, e não apenas instrumentais.

A diversidade de assuntos da informação abordados a partir das teorias de Habermas, e encontrados nesta busca, corresponde à riqueza do debate que a obra do filósofo e sociólogo alemão proporciona em todas as áreas. É importante destacar que artigos fazem uso das teorias para falar de internet, tecnologias de informação e comunicação e bibliotecas públicas. Isso mostra a amplitude e a atualidade das aplicações do pensamento crítico habermasiano.

\section{REFERÊNCIAS}

BRASIL. Coordenação de Aperfeiçoamento de Pessoal de Nível Superior. Portal de Periódicos da CAPES. Brasília, 2000. Disponível em:

$<h t t p: / / w w w . p e r i o d i c o s . c a p e s . g o v . b r / i n d e x . p h p ? o p t i o n=c o m \_p h o m e \& m n=68>$. Acesso em: 28 ago. 2013.

28 ago. 2013.

Buscar Base. Brasília, 2013. Disponível em: <http://zip.net/bllwMJ>. Acesso em:

CONSELHO NACIONAL DE DESENVOLVIMENTO CIENTIFICO E TECNOLÓGICO.

Tabela de áreas do conhecimento. Brasília. Disponível em:

<http://www.cnpq.br/documents/10157/186158/TabeladeAreasdoConhecimento.pdf>. Acesso em: 28 ago. 2013.

GONZÁLEZ DE GOMÉZ, Maria Nélida. Habermas, informação e argumentação. In: PINZANI, Alessandro; LIMA, Clóvis Montenegro de; DUTRA, Delamar V. O pensamento vivo de Habermas: uma visão interdisciplinar. Florianópolis: NEFIPO, 2009. p. 115-138.

HABERMAS, Jürgen. Consciência moral e agir comunicativo. Rio de Janeiro: Tempo Brasileiro, 1989.

Brasileiro, 1990.

Pensamento pós-metafísico: estudos filosóficos. Rio de Janeiro: Tempo 
Teoria do agir comunicativo. São Paulo: WMF Martins Fontes, 2012. 2. v.

Teoria de la acción comunicativa II: racionalidad de la acción y racionalización social. Madri: Taurus, 1987.

. Verdade e justificação: ensaios filosóficos. São Paulo: Loyola, 2004.

LIMA, Clóvis Ricardo Montenegro de; GONZÁLEZ DE GOMÉZ, Maria Nélida. Habermas, informação e argumentação. Linguagem, informação e novas dinâmicas sociais

contemporâneas. Liinc em Revista, Rio de Janeiro, v. 6, n. 2, p. 153-154, set. 2010.

PINZANI, Alessandro. Habermas. Porto Alegre: Artmed, 2009.

VIZEU, Fábio. Ação comunicativa e estudos organizacionais. RAE: Revista de

Administração de Empresas, São Paulo, v. 45, n. 4, dez. 2005. Disponível em:

$<$ http://www.scielo.br/scielo.php?script=sci_arttext\&pid=S0034-

$75902005000400002 \&$ Ing=en\&nrm=iso >. Acesso em: 18 nov. 2013.

\section{Title}

Habermas in the literature of information science: research publications in "Library and Information Science Abstracts" (LISA)

\section{Abstract}

Introduction: This paper presents issues related to Jürgen Habermas in the literature of information science, with emphasis on the discussion of the relationship between information and language and identifying the main issues of the information found.

Objective: To identify Jürgen Habermas in Information Science literature.

Methodology: Research on studies published in Library and Information Science Abstracts.

Results: Influence of Jürgen Habermas in Information Science scientific articles with emphasis on the "Theory of Communicative Action" and "Public Sphere".

Conclusion: Jürgen Habermas can provide theoretical and methodological references for studies and research in information science, especially those that require critical insights or innovative.

Keywords: Habermas. Information science. Library and information science abstracts.

\section{Título}

Habermas en la literatura de la ciencia de la información: publicaciones de investigación en "Library and Information Science Abstracts" (LISA)

\section{Resumen}


Introducción: Este trabajo presenta temas relacionados con Jürgen Habermas en la literatura de ciencias de la información, con énfasis en la discusión de la relación entre la información y el lenguaje y la identificación de los principales temas de la información encontrada.

Objetivo: Presentar el uso de Habermas en Información Literatura Ciencia.

Metodología: Esta exploración de los textos publicados en la Library and Information Science Abstracts

Resultados: Se indica el uso y la influencia de Jürgen Habermas en artículos científicos de Ciencias de la Información con énfasis en la "Teoría de la acción comunicativa" y "Esfera pública". Conclusiones: Jürgen Habermas puede proporcionar referencias teóricas y metodológicas para el estudio y la investigación en ciencias de la información, especialmente aquellos que requieren una visión crítica o innovadores.

Palabras clave: Habermas. Ciencias de la información. Library and information science abstracts.

Recebido em: 10.09.2013

Aceito em: 30.11 .2013 